КИРИЧЕНКО Г. І., к.т.н., доцент (Державний економіко-технологічний університет транспорту), директор з технічних питань компанії 5PL

\title{
Інтелектуальна система управління процесом доставки вантажу
}

Вирішення складної багатофакторної проблеми - управління процесом доставки вантажу, щзо за своєю суттю складає проблему координації функціонування транспортного комплексу в умовах нечіткості та неповної інформаційної визначеності, доцільно здійснити, використовуючи методологію концептуально логічного відображення та проектного моделювання транспортних систем.

Ключові слова: інформаційні технології, автоматизована система, управління перевезеннями.

\begin{abstract}
Вступ
Побудова системи управління процесами доставки вантажу пов'язана із створенням інтелектуальної системи управління, що реалізує стратегію, прийняття рішення та функціонування якої можливе в умовах, що постійно змінюються. У концепції інтелектуальної транспортної системи управління процесами доставки вантажу передбачено складання графіку доставки $[1,6]$ 3 розрахунком контрольно-часових точок (КЧТіј) за маршрутом слідування вантажу. Відхилення часу проходження контрольних точок $\left(\mathrm{KT}_{\mathrm{ij}}\right)$ від КЧТіј $\epsilon$ предметом управління диспетчерського (логістичного) центру з послідуючим вибором за допомогою системи підтримки прийняття рішення (СППР) оптимальної траєкторії з метою досягнення цілі - усунення або мінімізація відхилення. Треба врахувати, що у такій системі логічна, або смислова, обробка інформації превалює над обчислювальною та потребує створення моделей логіко - символьного рівня та використання баз знань.
\end{abstract}

У процесі прийняття рішення використовуються логічні роздуми людини (ЛПР), для яких неможлива або недоцільна формалізація критерію оцінки у вигляді систем математичних рівнянь, 3 іншого боку, опис критерію можливий у вигляді правил прийняття рішень як сукупності фраз природної мови, сформульованих лінгвістично. Методологія концептуально - логічного відображення та проектного моделювання транспортних систем [2] дозволяє моделювати судження диспетчерського, управлінського апарату при визначенні оптимальних рішень в управлінні доставкою

В силу об'єктивних умов транспортна система та іiі підсистеми являють собою, в ряді випадків, нечіткі множини; крім того, ці системи нестаціонарні, які працюють 3 недетермінованими об'єктами і на які впливає значна кількість факторів, в т. ч. природного

(C) Г.I. Кириченко, 2015 характеру. В автоматизованих системах утворюються нечіткі бази даних на підставі не завжди достовірної, повної та своєчасної інформації, в обробці якої приймає участь людина. При наявності таких характеристик та існуючому, назвемо його «принципом несумісності», коли складність системи і точність, 3 якою іiі можна описати традиційними математичними методами, суперечать один одному [3], для побудови моделі доцільно використовувати логіколінгвістичну модель (ЛЛМ). Вона відображає загальну смислову постановку задачі - дотримання мінімальних часових відхилень від контрольних часових точок за маршрутом слідування вантажу, при використанні якісних уявлень, які відповідають «людським» способам мислення диспетчерського апарату для здійсненні контролю доставки вантажу та прийнятті раціональних рішень управління.

\section{Концептуальна ціль системи управління}

Відхилення $(\Delta Ч)$ фактичного часу $\left(\right.$ КЧТ $\left.\phi_{\mathrm{ij}}\right)$ проходження $\mathrm{KT}_{\mathrm{ij}}$ від встановленого розрахунками та умовами договору часу (КЧТ д дij періодично (iз потрібною для кожної ситуації частотою) контролюється системою інформаційного моніторингу (CIM) та передається для прийняття рішення для управління процесом доставки вантажу до СППР.

Визначимо, що концептуальна ціль системи управління процесом доставки вантажів $є$ створення інтелектуальної системи контролю, за даними інформаційного моніторингу, відхилень від контрольних-часових точок, встановлених договором, для прийняття рішення з усунення відхилень.

У даних умовах був виконаний аналіз придатності методології концептуально-логічного відображення та проектного моделювання [2] складних транспортних організаційно-технічних систем для побудови моделі системи управління процесом доставки вантажів (УПДВ). Необхідно врахувати, що в цілому УПДВ залізничним транспортом є складною організаційнотехнічною системою, в якості її елементів виступають різнорідні категорії об'єктів та суб’ єктів управління. 
Суть використання методології наступна.

Визначимо область предметної діяльності (ОПД) виділимо із множини транспортних процесів систему, яка включає в себе підсистеме СІМ, що взаємодіє 3 СППР в загальному інформаційному просторі.

На першому етапі виконується декларативнографічний опис (ДГО) області предметної діяльності 3 доставки вантажів, при якому надається вербальний опис ОПД з різних точок зору. Основна задача ДГО міститься у визначенні семантики функціонування системи доставки вантажів залізницею: ціль та задачі; перелік функцій та структура, що реалізує ці функції; матеріальні, інформаційні, енергетичні потоки та графіки, принципи управління; стратегічні, тактичні і оперативні методи управління; механізми впливу та ресурси управління; критерії та показники,що характеризують ступень досягнення цілі функціонування системи i т. п. Тобто $є$ все, що необхідно i суттєво вже для формального опису процесів доставки вантажів, що досліджуються. Декларативно-графічний опис області предметної діяльності 3 доставки вантажів - це графічне відображення структури ОПД, який наданий на рис., та декларативний опис у плані проблематики рішення поставлених задач.

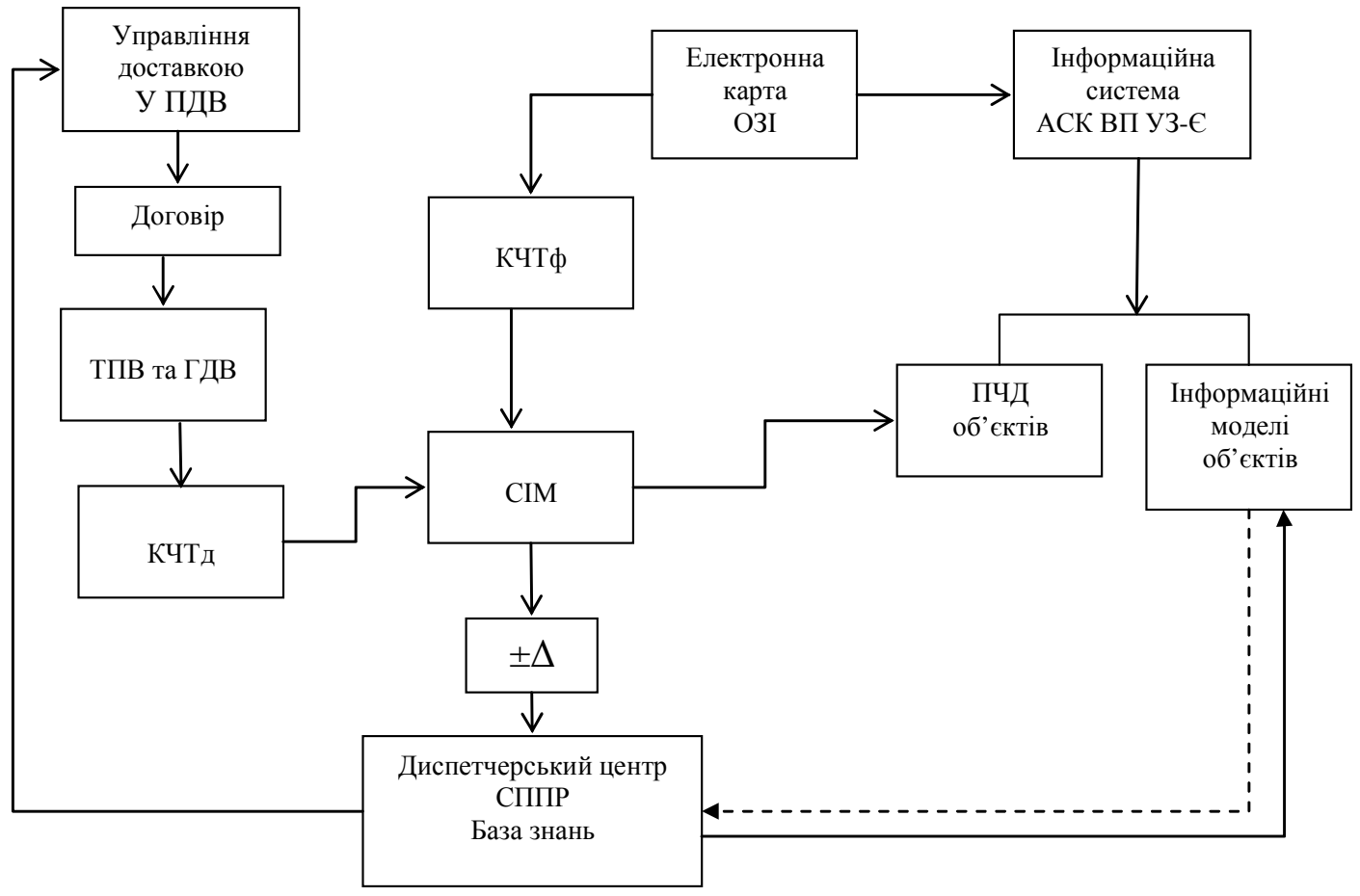

Рис. 1. Структура системи управління процесами доставки вантажів, функціонуючої в загальному інформаційному просторі залізниці

Результати ДГО використовуються на другому етапі реалізації методології, при побудові теоретикомножинних моделей (ТММ) у вигляді відображень, елементами якого є множина концептів, приймаючих участь у формуванні кінцевого концепту ТММ. Вхідні концепти моделей являють собою множини, в тому числі і в лінгвістичній формі. У свою чергу, концепти моделей можуть мати свої ТММ 3 більш високим ступенем деталізації. Відображення, у найбільш простому випадку, представляються у вигляді аналітичних залежностей, але частіше всього при дослідженні складних транспортних систем вони $€$ семантичним описом причинно-наслідкових зв'язків. Це приводить до необхідності залучення апарату математичної логіки.
Покажемо на прикладі методику взаємодії зв'язку: ДГО $\rightarrow$ ТММ. 3 цією метою розглянемо один 3 етапів технології [1] (що включає в себе операції та процеси, починаючи від підготовки вантажів до перевезення та закінчуючи доставкою «до дверей»), а саме модель взаємодії транспортних підсистем при прийомі та передачі вантажів, в тому числі при передачі вагонів на під’їзні колії морських торговельних портів. Необхідно зауважити, що іноді витрати часу та праці на підготовчо-кінцеві операції складають більше, ніж витрати у процесі перевезень залізницею. Тому при створенні моделі важливо врахувати вимоги рівномірної подачі вагонів в умовах наявних переробних спроможностей вантажних фронтів, що вимірюються у вагонах за добу. Крім того, в 
загальному контексті вирішення задачі, потрібно враховувати наступні параметри:

- переробна спроможність вантажного фронту (вагон) -M;

- розмір фронту одночасної подачі вагонів (вагон) $-\mathrm{c}$

- група вагонів одночасної обробки (вагон) - $\mathrm{k}_{1 \mathrm{j}}$;

- ознака можливості обробки однієї групи одночасно поданих вагонів кількома механізмами - V;

- вид операції (навантаження/розвантаження) $\mathrm{O}_{\Pi}$;

- час виконання вантажних операцій - $\mathrm{T}_{\text {ор }}\left(\mathrm{T}_{1}\right)$;

- час переподачі - $\mathrm{T}_{\mathrm{pp}}\left(\mathrm{T}_{2}\right.$ );

- кількість вагонів для переробки - $\mathrm{k}_{2}$;

- кількість механізмів - х;

- рід вантажу - z.

Всі вказані показники в тій чи іншій мірі приймають участь у визначенні часу подачі - $\mathrm{T}_{\text {кк }}$ (для дотримання умов рівномірності обслуговування під’їних колій) вагонів 3 вантажем, наприклад у в морський порт.

\section{Етапи створення проектної моделі системи управління}

Декларативно-графічний опис розглянутої стадії процесу доставки вантажів ілюструє, що вищеперераховані параметри мають внутрішні (перехресні) зв'язки, які на етапі ДГО не завжди можна відслідкувати. Даний факт призводить до надлишку математичних зусиль при визначенні $\mathrm{T}_{\text {кк }}$ зокрема. Інший аспект задачі полягає в тому, що на рівні ДГО неможна ручатися за те, що всі необхідні параметри враховуються, так як загальна математична модель побудована зразу з врахуванням всіх параметрів дуже громіздка, незручна при аналізуванні та не може ефективно відображати реальні процеси обробки вантажів, зокрема в морських портах. А питанні ставиться ширше - аналогічні проблеми виникають на прикордонних переходах і на терміналах промислових підприємств. Тому на першому етапі побудови теоретико-множинних моделей [4] уявимо метамодель $\mathrm{T}_{\text {кк }}$ у вигляді відображення, маючи на увазі, що всі концепти, які входять до складу моделі є множинами:

$$
\mathrm{m}_{1}: \mathrm{M} \times \mathrm{V} \times \mathrm{T}_{1} \times \mathrm{T}_{2} \times \mathrm{O}_{\Pi} \times \mathrm{L} \times \mathrm{T} \rightarrow \mathrm{T}_{\text {кк }} \times \mathrm{T} .
$$

В відображенні (1) введений ще один узагальнений концепт L - комплекс логічних правил, які застосовують диспетчери в процесі управління виконанням операцій навантаження/вивантаження вантажів на фронтах терміналів морських портів і т.п. Звичайні аналітичні моделі не дозволяють цього зробити, але застосовувана методологія концептуально-логістичного відображення i проектного моделювання транспортних організаційнотехнічних систем передбачає після побудови теоретико-множинних моделей і інфологічних моделей процесів, конкретизацію логіко-семантичних моделей, у яких саме логічна сторона відіграє основну роль.

Кожний концепт моделі $\mathrm{m}_{1} \epsilon$ або складовим показником, який має власну модель, або первинним параметром (аксіоматичним) - категорією даного процесу (стадія процесу). Процедуру побудови логікосемантичної моделі концептів метамоделі (1) будемо називати розкриванням моделі 2-го рівня:

$\mathrm{m}_{2}: \mathrm{X} \times \mathrm{C} \times \mathrm{K}_{1} \times \mathrm{T} \rightarrow \mathrm{M} \times \mathrm{T}$,

$\mathrm{m}_{3}: \mathrm{X} \times \mathrm{K}_{1} \times \mathrm{T} \rightarrow \mathrm{V} \times \mathrm{T}$,

$\mathrm{m}_{4}: \mathrm{K}_{2} \times \mathrm{C} \times \mathrm{O}_{\Pi} \times \mathrm{T} \rightarrow \mathrm{T}_{1} \times \mathrm{T}$,

$\mathrm{m}_{5}: \mathrm{K}_{2} \times \mathrm{C} \times \mathrm{O}_{\Pi} \times \mathrm{T}_{1} \times \mathrm{T} \rightarrow \mathrm{T}_{2} \times \mathrm{T}$,

$\mathrm{m}_{6}: \mathrm{O}_{п}=\left\{\mathrm{o}_{\Pi 1}, \mathrm{o}_{\text {п2}}, \ldots, \mathrm{o}_{\text {п m }}\right\} ; \sup \mathrm{O}_{\text {п }} \equiv \mathrm{O}_{\text {пm }} ; \inf \mathrm{O}_{\text {п }}=\mathrm{o}_{\text {п1 }}$, $\mathrm{O}_{\text {пі }} \in \mathrm{O}_{\text {пा }}, \quad \mathrm{i}=1, m$.

В свою чергу, деталізацію концептів моделей $\mathrm{m}_{2}-\mathrm{m}_{5}$ можливо також виконати 3 врахуванням тих параметрів процесів доставки вантажів, від яких вони функціонально залежать - розкриття моделей 3-го рівня і так далі. Глибина розкриття моделей залежить в цілому від потреб в їх деталізації. Перейдемо до важливої складової метамоделі (1) - комплексу логічних правил, які застосовуються диспетчерським складом. На сьогодні існує значна кількість методів представлення знань та професійної логіки мислення управлінського персоналу - правила, фрейми, нейтрони, семантичні мережі, логіка і т.П. Проте, тільки продуковані правила дозволяють в доволі зрозумілому вигляді осягнути логіку міркувань, так як вони виражають знання у вигляді продукованого типу

ЯКЩО $\mathrm{A}=\mathrm{B} \& \mathrm{~B}=\mathrm{C}$ TO A=C

Правило (8) в реальних базах знань мають різний вигляд і глибина вкладень в нього інших продукованих правил може досягати кількох сотень.

В якості змінних $\mathrm{A}, \ldots . ., \mathrm{K}$ виступають посилання (висловлювання судження, аксіоми, міркування та ін.), які володіють семантикою області предметної діяльності - мультимодальна доставка вантажів.

Декларативно - графічний опис та теоретикомножинні моделі надають можливість побудувати інфологічні моделі (ІЛМ) системи 3 описом потоків інформаційних елементів різної складності. При цьому слід виділяти, або статистично визначати такі показники як: достовірність, повноту, визначеність, безперервність інформації, що циркулює у системі. Декларативно - графічний опис, ТММ та ІЛМ Ту сукупності являють собою концептуальну модель (КМ) системи, що досліджується.

Концептуальна модель - множинне відображення цілей та задач управління процесами доставки вантажів, як аналітичних $\mathrm{i}$ семантичних функцій 
моделі, на множині концептів - аргументів моделі, у термінах та виділених категоріях інформаційного моніторингу та системи прийняття рішення, виходячи iз результатів декларативно - графічного опису, побудови теоретико- множинних i інфологічних моделей ОПД. Вони відображають аспекти функціонування моніторингу та системи прийняття рішення. Наприклад: ДГО структури інформаційного моніторингу, процесуальна ТММ, теоретико множинна модель ситуаційного управління, ІЛМ моніторингу процесу доставки вантажу і т.п.

Наступний етап складається із створення логіко семантичних моделей (ЛСМ) з використанням апаратів математичної логіки та семантичного аналізу. Ці моделі утворюють основу для побудови вузькопрофесійних баз знань, що $є$ невід'ємною частиною системи прийняття рішення. Бази знань створюються окремо за сукупністю основоположних знань i окремо за фактографічними знаннями. Вищенаведені описи та моделі служать для реалізації програмно-конструкторського опису (ПКО) системи управління доставкою вантажів на базі сучасних інформаційних технологій.

Разом логіко-семантична модель i програмноконструкторський опис являють логіко-лінгвистичну модель (ЛЛМ). Сукупність КМ та ЛЛМ надає можливість реалізувати узагальнену проектну модель системи [5] управління процесом доставки вантажів (ПМ). 3 урахуванням значного рівня невизначеності в аналітиці та семантиці концептів моделей вони мають нечіткий характер, при створенні моделей доцільно використовувати апарат нечіткої логіки Заде (теорія можливостей).

\section{Висновки}

Створення системи управління процесом доставки вантажу, що дозволяє прийняття рішення, спрямоване на дотримання часових характеристик, встановлених договором, доцільно здійснювати використовуючи методологію концептуально - логічного відображення та проектного моделювання транспортних систем, шляхом побудови імітаційних моделей. Такий підхід до створення системи управління дозволяє моделювати судження диспетчерського, управлінського апарату 3 координації функціонування транспортного комплексу при здійсненні моніторингу на базі існуючих сучасних інформаційних технологій управління.

\section{Література}

1. Кириченко Г. І. Проблематика застосування інформаційних технологій в управлінні процесами доставки вантажу Збірник наукових статей «Проблеми транспорту». - Вип. 9. - Київ: НТУ, 2012, - c. 17-27.

2. Петрашевский Л.П., Кириченко А.І. Пути повышения эффективности управления процессами доставки грузов при мультимодальных перевозках Збірник наукових статей «Проблеми транспорту». - Вип. 9. Київ:НТУ, 2012, - с. 3-16.

3. Усков А.А., Кузьмин А.В. Интеллектуальные технологии управления. Искусственные нейронные сети и нечёткая логика.- М. : Горячая линия-Телеком, 2004. - С. 143: ил., рос.

4. Н. Бурмаки. Теория множеств. М.: Книжный дом «Либроком», 2010.- С. 456.

5. Петрашевський О.Л., Данилевский В.В., Цымбал Н.Н. Адаптация методологии концептуально-логического отображения и проектного моделирования транспортных систем к задачам управления проектами. Київ. Проблеми транспорту. Збірник наукових праць.- 2010.-Випуск 7.-С. 56-60.

6. Кириченко Г.І. Концепція інтелектуальної транспортної системи управління процесами доставки вантажу. Залізничний транспорт України. 2013. - №1. - C. 37-40.

Кириченко А.И. Интеллектуальная система управления процессом доставки груза. Решение сложной многофакторной проблемы - управления доставкой груза, что по своей сути составляет проблему координации функционирования транспортного комплекса в условиях нечёткости и не полной информационной определённости, целесообразно осуществить, используя методологию концептуально-логического отображения и проектного моделирования.

Ключевые слова: информационные технологии, автоматизированная система, управление перевозками.

Hanna Kyrychenko. Intelligence system of a cargo delivery process management. The solution of a complex multifactorial problem - cargo delivery management (being per se a problem of coordination of transport complex functioning under fuzzy conditions and the conditions of incomplete information certainty), is advisable to carry out using the methodology of conceptual-logical mapping and design modeling.

Key words: informational technologies, automatized system, transportation management.

Рецензент д.т.н., професор Мироненко В.К. (ДЕТУТ)

Поступила 01.09.20152.

Кириченко А.И., к.т.н., доцент (ГЭТУТ, Киев, Украина). Директор по техническим вопросам компании 5PL

Hanna Kyrychenko, Technical director 5PL. Candidate of technical Sciences, docent (State Economic and Technological University of Transport), Kyiv, Ukraine. 